\title{
“Empty Coruña?” Un dispositivo académico transdisciplinar para a abordaxe, dende unha perspectiva dos dereitos, da problemática urbana trala crise financeira
}

\author{
Lizancos, Plácido; Calo, Estefanía²; R. Beltrán, Sonia \\ ${ }^{1}$ Escola Técnica Superior de Arquitectura, Universidade da Coruña. \\ ${ }^{2}$ Facultade de Socioloxía, Universidade da Coruña. \\ ${ }^{3}$ Mestrado de Rehabilitación Arquitectónica, Universidade da Coruña.
}

\section{RESUMO}

0 curso de verán "Empty Coruña? inhabited processes: mid crisis urban transformation" nace como unha experiencia educativa con orientación transdisciplinar. Busca analizar e investigar os efectos da crise financeira no espazo da cidade da Coruña desde diferentes perspectivas e actividades para acadar unha visión integradora da situación. Neste artigo presentamos as diferentes motivacións teóricas e as cuestións prácticas que se desenvolveron nun curso que pretende acercar a academia ás necesidades contemporáneas da nosa sociedade.

PALABRAS CLAVE: crise, baleiro urbano, cidade, vivenda, taller multidisciplinar. 


\section{CITA RECOMENDADA:}

Lizancos, P.; Calo, E.; R. Beltrán, S. (2019): “Empty Coruña?” Un dispositivo académico transdisciplinar para a abordaxe, dende unha perspectiva dos dereitos, da problemática urbana trala crise financeira. En De la Torre Fernández, E. (ed.) (2019). Contextos universitarios transformadores: construíndo espazos de aprendizaxe. III Xornadas de Innovación Docente. Cufie. Universidade da Coruña. A Coruña (pág. 345-358).

DOI capítulo: https://doi.org/10.17979/spudc.9788497497121.345

DOl libro: https://doi.org/10.17979/spudc.9788497497121

\section{ABSTRACT}

Summer course "Empty Coruña? inhabited processes: mid crisis urban transformation" is born as an educational experience with transdisciplinary orientation. It looks for to analyze and research the effects of the financial crisis in the space of the city of A Coruña from different perspectives and activities to achieve an integrative vision of the situation. In this article we present the various theoretical motivations and the practical questions that were developed in a course adressed to land academia on contemporary social issues.

KEY WORDS: crisis, urban voids, city, housing, multidisciplinary workshop 


\section{INTRODUCIÓN}

A crise financeira de 2008 afectou de forma significativa 0 dereito á vivenda e á cidade. En España estímanse 500.000 edificios inacabados, incompletos, forzosamente abandonados ou vacantes e mesmo fragmentos enteiros de cidade, planificada, construída e urbanizada. No seu conxunto estes indicadores espaciais veñen a empeorar unha situación que para algúns autores como Lefebvre (1976a) podería ser cualificada como estrutural e incluso unha verdadeira institución (Lefebvre, 1976b).

A vivenda e a cidade convertéronse en mercadorías que segregan o espazo restrinxindo os dereitos ${ }^{i}$ a determinados grupos socias. "Na cidade neoliberal que 0 capital constrúe para absorber os excedentes que ela mesma creaii, as clases acomodadas son libres e as que carecen de medios non. A liberdade da cidade foi usurpada por unha elite financeira e debe ser recuperada polo movementos sociais que deben modificar a traxectoria do capital" (Harvey, 2008, p. 28). Se a esta situación lle engadimos as estratexias de financiarización das economías capitalistas occidentais podemos falar dunha radical reordenación das escalas territoriais (Rodríguez López, 2013).

Segundo Castells (2004 (1974)) estamos ante novas formas urbanas e de articulación social, unha nova configuración urbana con maiores desigualdades sociais, económicas e espaciais que requiren unha nova forma de xestión (Sassen, 1994). A construción do espazo urbano é resultado das accións, das prácticas, das relacións e das experiencias sociais: non hai relacións sociais sen espazo, de igual xeito que non hai espazo sen relacións sociais (Lefebvre, 2013). Polo tanto, para comprender a dimensión espacial, segundo Harvey (1992), é esencial para comprender realmente os procesos sociais.

A escala local pode axudarnos a comprender esta relación. Na Coruña, estímase que $020 \%$ das vivendas en disposición de ser usadas están vacantes producindo unha fragmentación crecente que afecta 0 dereito á cidade e á vivenda. Ante esta situación organizouse un programa pedagóxico experimental baseado nunha perspectiva transdisciplinar. A base teórica da análise é a Actor Network Theory (ANT) de Latour (1996). A metodoloxía implica sintetizar 
as narrativas cidadás a través dun mapeado, da investigación visual de material e arquivos públicos e a creación dun modelo centrado na Axencia, nos Obxectos e nos Procesos. A través destes modelos podemos analizar e visibilizar a complexidade e contradicións da arquitectura social para aplicar unha investigación que identifique, conceptualice e politice proposicións críticas.

\section{DESCRICIÓN DA EXPERIENCIA}

0 curso de verán "Empty Coruña? inhabited processes: mid crisis urban transformation" nace como unha experiencia educativa con orientación transdisciplinar, porque entendemos que é preciso que a análise do espazo e da urbanización se realice dende unha perspectiva integradora (Lefebvre, 2013). Esta iniciativa transita pola influencia recibida e exercida entre disciplinas como a arquitectura, a socioloxía, a economía, o dereito, a enxeñeira ou a antropoloxía entre outras.

Galicia, onde se estima que 50.000 edificios permanecen abandonados ou inacabados, sufriu vivamente a crise financeira de 2008 que enraíza con outras crises sistémicas anteriores. Nunha escala local, na área urbana da Coruña, uns 2.000 elementos arquitectónicos de todo tipo e arredor dun $20 \%$ das vivendas do parque inmobiliario foron deixadas baleiras debido aos desafiuzamentos, á insolvencia ou á quebra do mercado deixando tras de si un desolador e doloroso panorama de Casas sen Xente, Xente sen Casas. "EMPTY CORUÑA?" confórmase como un obradoiro universitario, transdisciplinar, participativo e autoxestionado que identifica para avanzar nas respostas aos grandes desafíos dos que raramente se fala na universidade. 


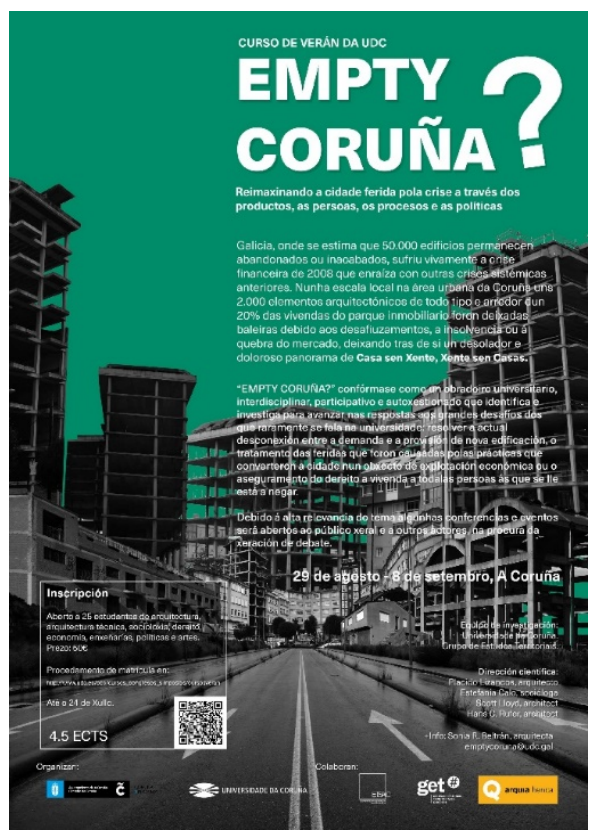

Imaxe 1. Cartaz do curso

Ese obxectivo foi traballado a partir dunha estrutura académica baseada na realización dun workshop, enfocado na análise de sete casos de estudo escollidos pola súa relevancia académica. 0 workshop desenvolveuse durante 10 días, entre 030 de agosto e 08 de setembro, concluíndo coa implementación dunha exposición na que se mostraron os resultados do traballo alcanzado.

0 número de inscritos foi de 25 persoas. 0 número de profesores implicados superou a decena, contando con dous arquitectos de Zurich -Scott Lloyd e Hans Rufer- que dirixiron 0 taller, motivo polo cal o curso de desenvolveu fundamentalmente en lingua inglesa.

0 estudantado foi dividido en 7 grupos. Cada grupo traballou cun caso particular de cada unha das tipoloxías establecidas. Os grupos elixiron o estudo de caso de entre 101 exemplos posibles que se lles presentaron. A súa análise centrouse no estudo dos procesos, axentes e obxectos implicados en cada un dos casos. 


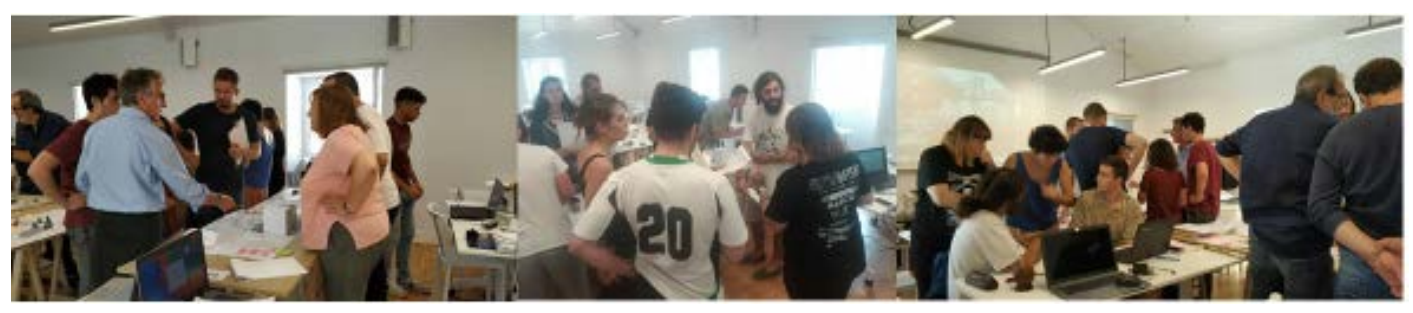

Imaxe 2. Workshop

Este workshop foi acompañado de sesións teóricas que tiveron por argumento as diversas temáticas do habitat: dereito, tecnoloxía, medio ambiente, ética, finanzas, urbanismo e deseño. Estas clases supuxeron a base teórica que lles permitiu aos grupos avanzar na investigación dos diferentes casos en relación a diferentes disciplinas.

Houbo outras actividades complementarias como:

- Roteiros guiados pola cidade

- Debates e discusións dirixidas

- Xogos de rol

- Clases na rúa. 


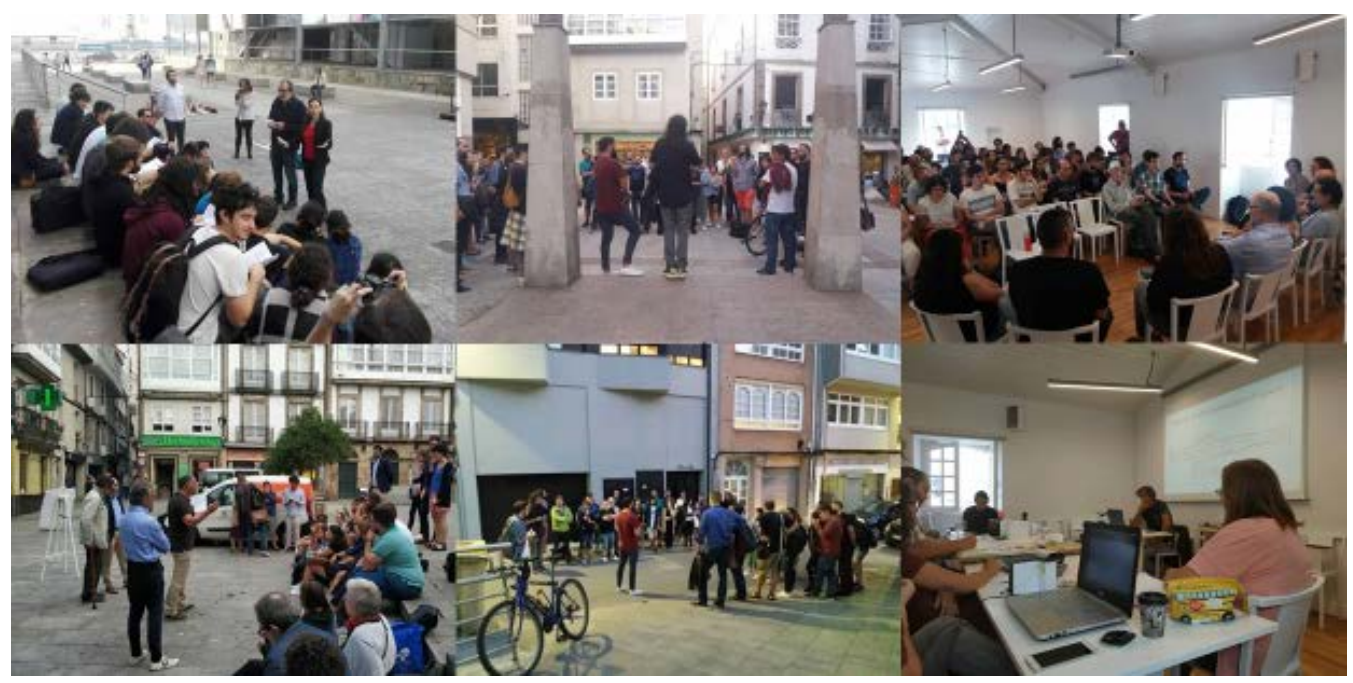

Imaxe 3. Aulas na rúa (dereita), roteiros (centro), debates e discusións (dereita)

Este curso apoiouse sobre un traballo de investigación previo, onde o profesorado implicado, xunto cun amplo grupo de alumnos e alumnas da UDC cartografaron, debuxaron e documentaron os materias utilizados no curso de verán.

A actividade inaugurouse e pechouse no Cárcere Vello da Coruña. A partir de aí desenvolveuse no Centro Cívico da Cidade Vella da Coruña en horario de 8:30 a 23 de luns a domingo.

0 grupo de traballo foi moi amplio:

a. Dirección: Plácido Lizancos, arquitecto Estefanía Calo, socióloga, Hans-Christian Rufer, arquitec-toScott Lloyd, arquitecto

b. Coordinadora: Sonia R. Beltrán, arquitecta.

c. Research Team: Aida Vidal Balea, Amal Nnechachi Bounous, Beatriz Fernández Armada, David Pereira, Estefanía Tarrío Maneiro, Estéfano Oliveira Pereira, Jorge López Fernández, Juan Froján Castro, Juan Quintela, Julia Fernández Sáez, Lucía Escrigas Rodríguez, Michael Juan Sierra, Noemi Zanón, Paolo Paradiso, Sergio Artime Muñiz, Xaquín Lizancos. 
Para a realización deste curso contouse con diferentes entes colaboradores:

a. Grupo de Estudos Territoriais

b. Cartolab: grupo de enxeñeiros que creou a ferramenta emapic.

c. Concello da Coruña. Que prestou as instalacións do Centro cívico da Cidade Vella da Coruña en horario ordinario, durante dez días, sen custe algún.

d. Concello de Miño. Que puxo a disposición do Curso un autobús para desprazarse a Miño e visitar un dos casos de estudo.

e. Escola de Arquitectura da Coruña. Que cedeu dende abril de 2018 a xaneiro de 2019 un espazo, equipado, para uso propio da comunidade e equipo de investigación de Empty Coruña.

f. Proxecto Cárcere: cedeu as instalacións para a apertura e clausura do curso xunto coas exposicións.

g. Exposición Spanish Dream do colectivo Cadelas Verdes; Ana Amado, Marta Marcos, Luz Paz

h. Cartografía Social do Dereito ao Hábitat. Elaborada por Laura Cruz, Juan José Bueno e Roberto Suárez e desenvolvida polo alumnado do Grado de Educación Social e Pedagoxía, Socioloxía e Psicoloxía das Artes Plásticas e Visuais do Mestrado en Profesorado de Secundaria Obrigatoria, co asesoramento do Estudo Rurban e Arquitectura sen Fronteiras

i. Juan Pirola Lorezo, elaboración dunha reportaxe centrada na cuestión residencial.

\section{RESULTADOS}

\section{Ferramenta emapic:}

0 grupo Cartolab elaborou unha ferramenta en base á aplicación emapic para que a cidadanía poida xeolocalizar espazos baleiros na cidades. Desta forma, conséguese que a poboación participe do proceso de investigación. A ferramenta está accesible en:

https://emapic.es/survey/c1HlyA 


\section{Páxina web:}

Foi implementada unha páxina web bilingüe, en inglés e galego, para o uso do curso e do proxecto de investigación, sita en: http://emptycoruna.net

\section{Mapeado:}

0 grupo de investigación do estudantado colaborador realizou un mapeado das localización dos diferentes espazos baleiros na cidade e na súa contorna. 


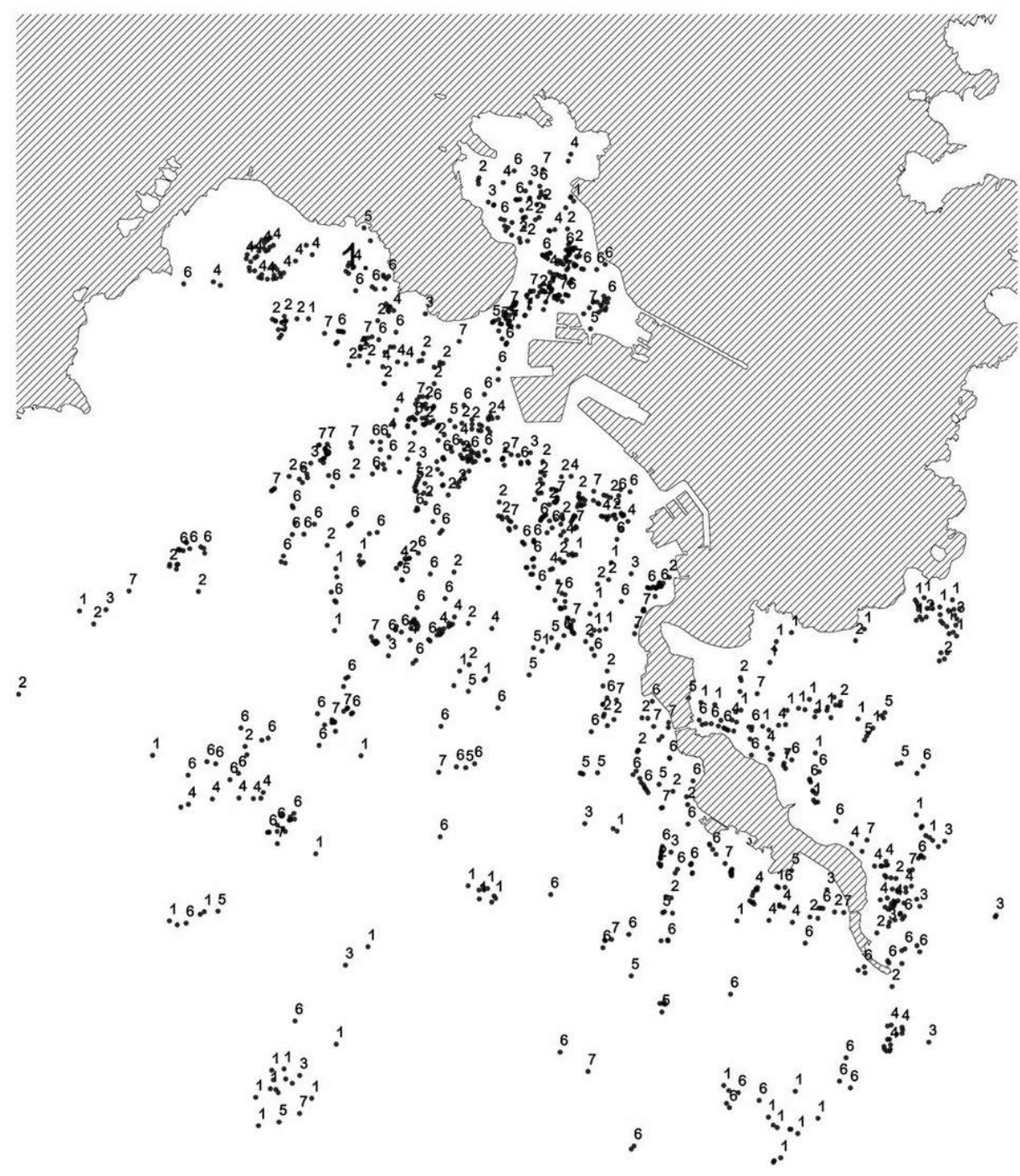

Locations of seven typologies of empty buildings and urban sites

1. Process without process [ 149 documented cases] Developed sites with no top structure

2. Expectant process [251 documented cases] Empty urban plots

3. Stopped process [54 documented cases] An incomplete construction process

4. Partially completed [185 documented cases] Construction with only some stages completed

5. Never used buildings [ 66 documented cases] Never occupied completed buildings

6. Abandoned buildings [ 460 documented cases] Completed buildings since abandoned

7. Ruin [188 documented cases] Partially collapsed building

September, 2018

Mapa 1. Clasificación e localización das 7 tipoloxías 


\section{Exposición:}

Como resultado principal podemos presentar a exposición realizada polo estudantado que acudiu ao curso. Cada grupo investigou sobre un estudo de caso concreto analizando 0 proceso, os axentes implicados e o obxecto resultante.
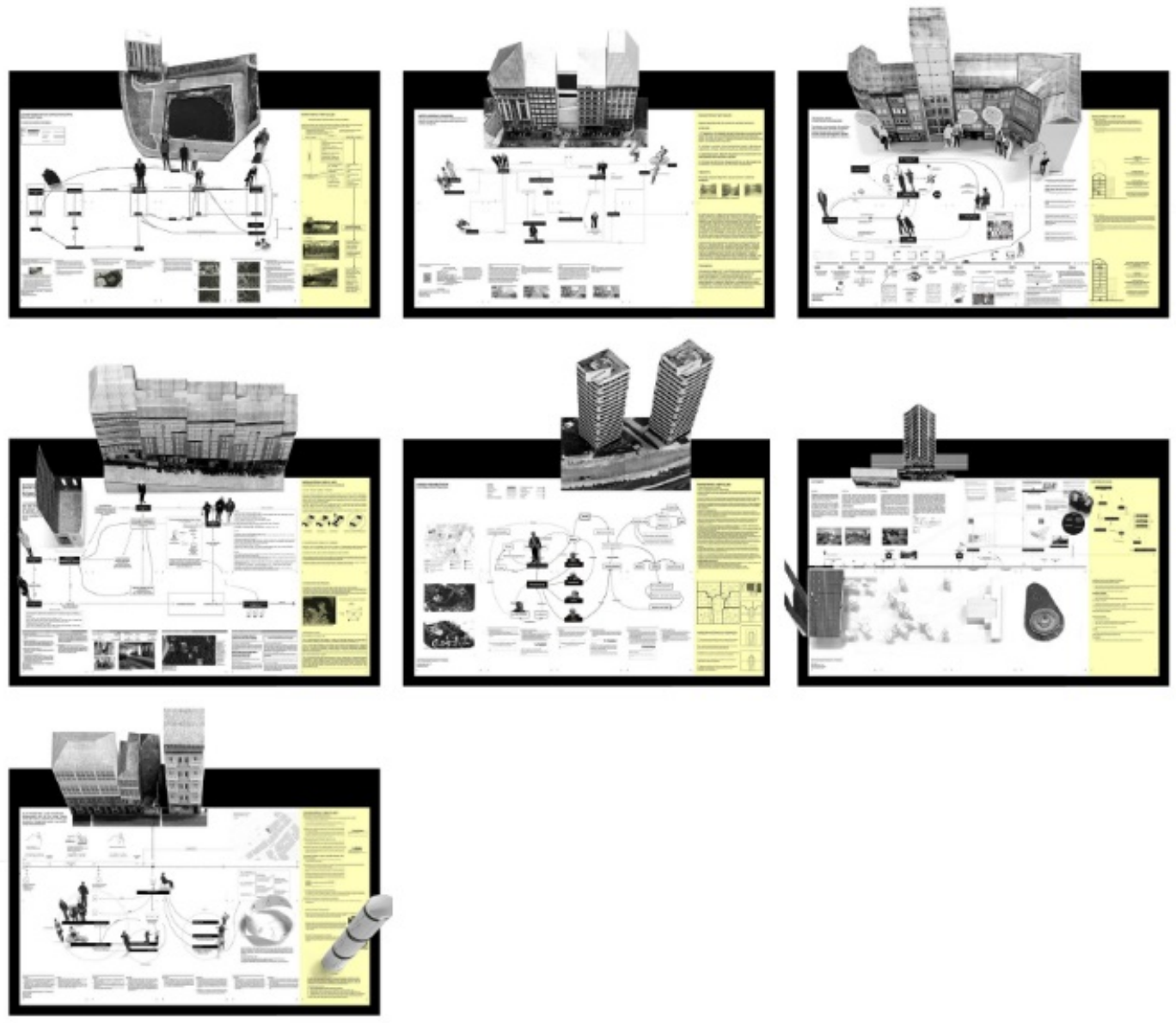

Imaxe 4. Maquetas da exposición 


\section{Xornadas cidadás:}

0 curso, debido a súa temática e ao esforzo da organización, recibiu unha grande resposta por parte dos medios de comunicación social. A finais de novembro de 2018 realizouse un evento Cidadán organizado polo Concello da Coruña, na Fundación Luis Seoane da Coruña.

Estas xornadas acolleron en dous días conferencias e debates de diferentes expertos, así como de axentes sociais e representantes políticos da cidade. Algunhas das persoas invitadas doutras partes do estado foron Ethel Baraona Phol (Barcelona), Eva Morales (Málaga) e n’UNDO (Madrid) que expuxeron a súa visión dunha mesma problemática en diferentes partes do mundo.

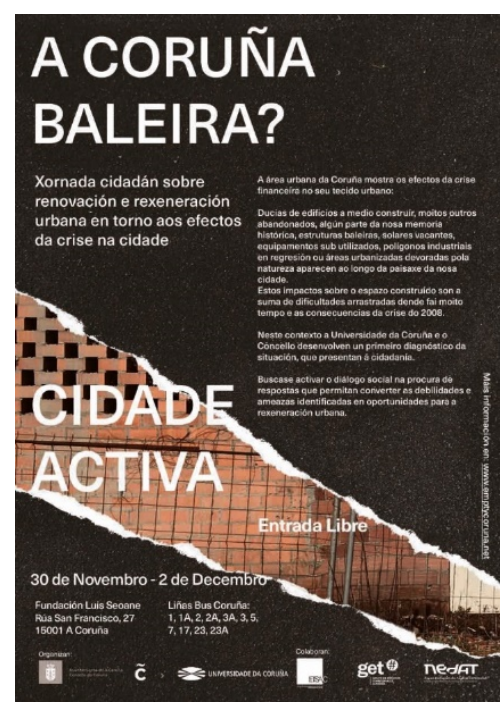

Imaxe 5. Cartaz Xornadas Cidadás

\section{Reportaxe:}

Outro dos resultados foi a elaboración dunha reportaxe audiovisual, "A Coruña Baleira?", na que se recollen diferentes perspectivas sobre a existencia do baleiro na cidade da Coruña, principalmente residencial. A través dunha metodoloxía de entrevistas abertas, recóllense varios discursos sobre a cuestión urbana na cidade. Para isto, sérvese de diferentes perfís: mulleres e homes de diferente orientación política, con coñecemento sobre a política de 
vivenda, o mercado residencial e con vivencias persoais relacionadas co dereito á vivenda e 0 dereito á cidade. Esta reportaxe está feita por un equipo formado por profesionais de socioloxía, de comunicación e de arquitectura entre outros, así como activistas sociais, que buscan recoller a realidade vivida polas/os afectadas/os. 0 tráiler está accesible en: https://www.youtube.com/watch?v=ZOGW65DF4Hg

\section{CONCLUSIÓNS}

A organización desta actividade docente foi complexa e longa. Houbo que compatibilizar 0 tempo e desexos das partes implicadas o que dificultou bastante o peche do programa.

A maior innovación deste curso foi a abordaxe do estudo dunha realidade social dende unha perspectiva transdisciplinar real. 0 estudantado puido asistir a diferentes sesións teóricas impartidas polo profesorado de diferentes disciplinas. Este feito reforzou a idea da necesidade de ter en conta diferentes perspectivas para abordar as problemáticas sociais, neste caso a problemática urbana que afecta o dereito á cidade e á vivenda.

Os resultados foron moi positivos. Parte do estudantado inscrito no curso participou de forma activa nas xornadas cidadáns e está interesado en continuar no proxecto a longo prazo.

\section{REFERENCIAS}

Castells, M. (2004(1974)). La cuestión urbana. Madrid: Siglo XXI.

Harvey, D. (1992). Urbanismo y desigualdad social [Social justice in the city] (6th ed.).

Madrid: Siglo XXI de España Editores, S.A.

Harvey, D. (2008). Derecho a la ciudad. New Left Review, 53, pp. 23-39.

Latour, B. (1996). On actor-network theory: A few clarifications. Soziale Welt, 47, pp. 369-381.

Lefebvre, H. (1976a). Espacio y política. Barcelona: RIGSA.

Lefebvre, H. (1976b). La revolución urbana ( $2^{\mathrm{a}}$ ed.). Madrid: Alianza Editorial.

Lefebvre, H. (2013). La producción del espacio [La production de I'espace 1974]. 
Madrid: Capitán Swing.

Rodríguez López, J. (2013). La vivienda. De los ajustes al banco malo. Economistas Extra, Vivienda Y Medio Ambiente, 135, pp. 227-237.

Sassen, S. (1994). El complejo urbano de una economía mundial. Revista Internacional De Ciencias Sociales, (139), pp. 55-78.

\footnotetext{
' Referímonos ao dereito á vivenda e á cidade.

ii A través do que Harvey (2008) denomina circuíto secundario da economía, unha modelidade de rotación do capital a través do contorno construído.
} 